\title{
Aprendizagem mediada na escolarização de educandos com autismo
}

\author{
Cláudia Roberto Soares de Macêdo \\ Rede Pública de Ensino do Estado do Rio Grande do Norte \\ Débora Regina de Paula Nunes \\ Universidade Federal do Rio Grande do Norte
}

\section{Resumo}

Um dos principais desafios encontrados no processo de escolarização de educandos com Transtorno do Espectro do Autismo (TEA), no contexto da escola regular, é a identificação de práticas pedagógicas eficazes. Nesse sentido, o objetivo deste estudo foi avaliar os efeitos de uma prática interventiva denominada Experiência de Aprendizagem Mediada (EAM), implementada por uma professora, no desempenho acadêmico e social de um aluno com TEA matriculado em uma turma de 40 ano do Ensino Fundamental. Um delineamento de pesquisa quase experimental intrassujeito indicou aumento na frequência de ocorrência de comportamentos mediadores da professora e avanços no desempenho acadêmico e social do aluno após a implementação da EAM.

Palavras-chave: Transtorno do Espectro do Autismo. Mediação pedagógica. Inclusão educacional.

\section{Mediated learning in educating students with autism}

\section{Abstract}

One of the main challenges encountered in educating students with Autism Spectrum Disorder (ASD) in regular schools is identifying effective teaching practices. The aim of this study was to evaluate the effects of an interventional practice entitled Mediated Learning Experience (MLE), implemented by a teacher, in the academic and social performance of a student with ASD enrolled in the fourth grade class. A single subject quasi-experimental research design indicated increased frequency of teacher mediating behavior and advances in the student's academic and social achievement following the EAM intervention.

Keywords: Autism. Pedagogic Mediation. School Inclusion. 
Aprendizagem mediada na escolarização de educandos com autismo

\section{Aprendizaje mediada en la educación de los estudiantes con autismo}

\section{Resumen}

Uno de los principales problemas encontrados en la educación de los alumnos con Trastorno del Espectro Autista (TEA) en las escuelas regulares es la identificación de las prácticas de enseñanza eficaces. El objetivo de este estudio fue evaluar los efectos de una práctica intervencionista titulado Experiencia de Aprendizaje Mediado (EAM), ejecutado por un profesor, en el rendimiento académico y social de un alumno con TEA matriculado en la clase de cuarto grado. Un diseño cuasi-experimental indicó aumento de la frecuencia de la conducta mediadora da maestro y los avances en el desarrollo académico y social del alumno después de la intervención EAM.

Palabras clave: Autismo. Mediación pedagógica. Inclusión Escolar.

\section{Introdução}

Classificado como distúrbio do neurodesenvolvimento, o Transtorno do Espectro do Autismo (TEA) chega a afetar 1 a cada 68 norte-americanos ICHRISTENSEN; BAIO; BRAUN; BILDE; CHARLES; CONSTANTINO; DANIELS; DURKIN; FITZGERALD; KURZIUS-SPENCER; LEE; PETTYGROVE; ROBINSON; SCHULZ; WELLS; WINGATE; ZAHORODNY; YEARGIN-ALLSOPP, 2016$)$ ou cerca de 600 mil brasileiros (PAULA; FOMBONNE; GADIA; TUCHMAN; ROSANOFF, 201 1). Nesse contexto investigativo, estudos recentes revelam desafios, para os profissionais da Educação, no que diz respeito ao processo de escolarização de alunos diagnosticados com TEA. Pesquisas de revisão publicadas no Brasil, nos últimos anos indicam, por exemplo, que as práticas pedagógicas usuais adotadas nas salas de aula, pouco têm favorecido a aprendizagem desse alunado (OLIVEIRA; PAULA, 2012; NUNES; AZEVEDO; SCHMIDT, 2013; NEVES; ANTONELLI; SILVA, CAPELLINI, 2014).

Na medida em que o professor é o principal responsável por favorecer o desenvolvimento cognitivo do aluno, torna-se necessário considerar o seu repertório de comportamento enquanto mediador do processo de aprendizagem (FARIAS; MARANHÃO; CUNHA, 2008; NASCIMENTO, 20 1 2). Na perspectiva sócio-histórica, a aprendizagem do educando com ou sem deficiência ocorre em situações interativas (VIGOTSKI, 1997). Com base nessa abordagem, Feverstein e colaboradores (1987) introduzem o conceito de 
Experiência de Aprendizagem Mediada (EAM), compreendida como a ação propositiva de um mediador, com maior nível de desenvolvimento, que seleciona, modifica, amplia e/ou interpreta os estímulos ambientais (imagens, objetos, tarefas, problemas etc.) para o aprendiz (FONSECA, 2002), tornando- o um ser humano mais autônomo e independente.

Conforme a Teoria da EAM, três critérios de mediação são essenciais para que aconteça uma situação de aprendizagem: a intencionalidade/reciprocidade, o significado e a transcendência (LIDZ, 2003; FARIAS; MARANHÃO; CUNHA, 2008; MAGALHÃES; CUNHA; SILVA, 20131. Na primeira classe incluem-se comportamentos que atuam nos estados de vigilância do educando, tendo como propósito modificar suas estruturas cognitivas (FARIAS; MARANHÃO; CUNHA, 2008; NASCIMENTO, 20121. Assim, o mediador auxilia o aprendiz a atentar para estímulos específicos a serem apreendidos e certifica-se de sua resposta. A mediação de intencionalidade é, portanto, caracterizada por uma relação de reciprocidade, em que tanto o aprendiz quanto o mediador são contemplados na interação. Em outras palavras, a intencionalidade e a reciprocidade ocorrem quando um mediador, intencionalmente, chama a atenção da criança para um estímulo específico do ambiente e, assim, ela emite a resposta desejada (FARIAS; MARANHÃO; CUNHA, 2008; CUNHA; MAGALHÃES, 20111.

Nos comportamentos de significação, correspondente à segunda classe descrita por Feurstein e colaboradores (1987), o mediador atribui um significado ao estímulo, salientando a sua importância. $\bigcirc$ objeto a ser apreendido deixa de ser neutro, instigando o aprendiz a aprofundar o seu conhecimento sobre o tópico ressaltado, elaborando novos significados ou generalizando o conteúdo aprendido. Para que o estímulo se torne significativo, é preciso que o mediador utilize formas verbais e não verbais de comunicação, incluindo-se expressões de afeto (FARIAS; MARANHÃO; CUNHA, 2008; NASCIMENTO, 2012).

Por fim, a mediação por transcendência diz respeito aos comportamentos que viabilizam a generalização do conhecimento. Nesse caso, o mediador auxilia o aprendiz a estabelecer conexões entre o que ele já sabe e o que aprenderá no futuro (LIDZ, 2003). Essa classe de comportamento permite relacionar suas experiências pessoais e imediatas a distintas situações e tarefas rotineiras e/ou futuras. Em termos gerais, é aprender a aprender (NASCIMENTO, 2012), favorecendo ao educando fazer inferências 
e construir/estabelecer regras explicativas sobre fenômenos que ocorrem ao seu redor.

Com o objetivo de operacionalizar os critérios de Aprendizagem Mediada decorrentes dos trabalhos de Feverstein e colaboradores (1987), Lidz (2003) criou a Mediated Learning Experience Rate Scale - MLE Scale (Escala de Avaliação da Experiência de Aprendizagem Mediada - Escala EAM), que avalia comportamentos mediadores entre díades em situações de interação. Em sua versão elaborada para professores, Lidz (2003) inclui, além dos três componentes de mediação previamente salientados (intencionalidade/reciprocidade, o significado e a transcendência), mais nove componentes: a atenção partilhada, a experiência partilhada, a regulação na tarefa, o elogio, o desafio, a diferenciação psicológica, a responsividade contingente, o envolvimento afetivo e a mudança. Supostamente, esses nove componentes inexistem em todas as culturas. Todavia, esses poderão assumir uma função estruturante e determinante no ato de mediar (LIDZ, 2003; NASCIMENTO, 2012 ).

Nos últimos anos, a escala EAM, juntamente com suas adaptações têm sido empregadas em estudos avaliativos do processo de interação mãe-criança (CUNHA, 2004; CUNHA; ENUMO; CANAL, 2006), terapeuta-paciente (CUNHA; GUIDORENE, 2009) e professor-aluno (FARIAS; MARANHÃO; CUNHA, 2008; YEOW, 2011 ; NASCIMENTO, 2012; FÉLIX, 20131. Dentre esses, ganha destaque uma pesquisa nacional tendo como participantes educandos com TEA, no contexto da educação infantil (FARIAS; MARANHÃO; CUNHA, 2008).

Com o propósito de ampliar as pesquisas referentes à aplicabilidade da EAM, como prática interventiva com educandos com autismo, o objetivo geral do presente estudo foi analisar os efeitos de uma proposta de intervenção, baseada na EAM, no comportamento mediador de uma professora e o desempenho acadêmico e social de uma criança com TEA, inserida no $4^{\circ}$ ano do Ensino Fundamental. Como desdobramentos desse objetivo, o presente estudo visa (a) Detalhar as práticas pedagógicas utilizadas pelo professor com uma criança com TEA; (b) Propor procedimentos de intervenção, preconizados pela EAM, com vistas ao desenvolvimento de competências acadêmicas e sociais desse aluno; (c) Avaliar os efeitos do trabalho de intervenção na prática do professor desse aluno; e (d) Avaliar o grau de desempenho acadêmico e social do aluno no decorrer do trabalho de pesquisa. 


\section{Método}

Os participantes dessa pesquisa foram Aluizio, um aluno diagnosticado como autista, sua mãe e Ana, a professora. No período de realização do estudo, o aluno tinha nove anos de idade, tendo recebido o laudo de autismo aos três. Na ocasião, não se comunicava oralmente, demonstrava déficits nas habilidades de interação social e comportamentos auto e heterolesivos. Costumava fazer uso de objetos para fins de autoestimulação llevava objetos e secreções expelidas pelo corpo à boca), além de apresentar, com frequência, comportamentos autoestimulatórios (estereotipias motoras, como leves balanceios). Os resultados da avaliação desse aluno, conforme a escala Childhood Autism Rating Scale - CARS (PEREIRA; RIESGO; WAGNER, 2008), aplicado em conjunto com a mãe e a professora, indicaram um quadro de autismo grave, perfazendo um total de 49 pontos.

A mãe tinha 40 anos, segundo grau completo, era solteira, trabalhava como autônoma e vivia com três filhos.

Ana, a professora de 34 anos de idade, era formada em Pedagogia e atuava como docente há treze anos na escola onde a pesquisa foi realizada. Ela era pós-graduada em Ensino Médio, não possuía formação na área de Educação Especial e desconhecia as características do TEA.

A primeira autora deste artigo, supervisionada pela segunda autora, ałuou como agente de intervenção. Possuía formação em Pedagogia e especialização em Linguística e Ensino de Língua Portuguesa. Durante a realização da pesquisa, trabalhava como professora da rede pública de ensino e em Sala de Recursos Multifuncionais. No presente manuscrito, essa participante será designada como pesquisadora.

Oestudo contou, também, com uma assistente de pesquisa, responsável por codificar as sessões experimentais. Tratava-se de aluna que, na ocasião, frequentava o $7^{\circ}$ período do curso de Pedagogia.

trabalho de pesquisa foi conduzido no ambiente de uma sala do $4^{\circ}$ ano do Ensino Fundamental de uma escola particular de pequeno porte, localizada em um bairro de classe média da cidade de Parnamirim - Rio Grande do Norte.

Os materiais utilizados na pesquisa incluíram uma filmadora digital, um notebook, materiais acadêmicos (jogos, papéis, cola, tesoura etc.) e 
pictogramas. Adicionalmente, na fase interventiva do estudo, textos acadêmicos versando sobre temáticas estudadas durante a capacitação da docente foram incluídos.

Os instrumentos de pesquisa utilizados abrangeram dois roteiros de entrevista, um diário de campo, a escala CARS, que avalia o grau de autismo, e a escala EAM para professores (LIDZ, 2003).

A escala EAM para professores se constitui de um instrumento de medida/coleta de dados, para fins de análise qualitativa. Essa escala permite avaliar doze comportamentos interativos considerados essenciais para a aprendizagem. $\bigcirc$ referido instrumento foi criado para auxiliar o docente a identificar comportamentos mediadores empregados em contextos escolares (LIDZ, 2003). Esses comportamentos, descritos no Quadro 1, são avaliados por meio de 34 afirmativas (itens) referentes às interações do professor com o aluno em contexto escolar. Por uma Escala Likert de 4 pontos, cada afirmativa é então pontuada de 1 a 4: sendo 4 - comportamento evidente em alto grau e 1 -comportamento não evidente.

Em seguida, os itens são agrupados em blocos de asserções, perfazendo um total de doze, de acordo com os respectivos componentes lex: perguntas 1, 2 e 3 da escala referem-se ao componente intencionalidade) e a pontuação média dos itens calculada lex.: pl = 3; p2 = 1; p3 = 4; pontuação média de intencionalidade $=2,7)$. Dessa forma, é possível calcular o nível de mediação de cada componente, ao qual pode ser atribuída pontuação máxima de 4 pontos e mínima de 1 ponto. Se forem agrupados todos os doze blocos de asserções/itens, a pontuação máxima atingirá a marca de 48 pontos e a mínima de 12 pontos. Em síntese, quanto mais alta a pontuação, melhor o nível de mediação do professor. 


\section{Quadro 1 \\ Definição dos 12 componentes de mediação avaliados pela Escala de Aprendizagem Mediada}

Definição do componente

Intencionalidade - auxiliar o aluno a atentar para estímulos específicos a serem apreendidos em uma tarefa/como engajar-se na tarefa.

Significação - auxiliar o aluno a atribuir significados a um estímulo neutro. Inclui o uso de gestos, tons de voz variados, materiais concretos etc.

Transcendência - expandir o significado de uma tarefa/atividade para além da situação imediata do aluno. Encorajá-lo a fazer inferências, a considerar as implicações para a ocorrência de um dado fenômeno.

Atenção partilhada - referenciar estímulos que são foco de interesse do aluno.

Experiência partilhada - compartilhar pensamentos, sentimentos ou experiências com o aluno, tendo como foco a temática da tarefa.

Regulação na tarefa - ajustar a tarefa ao nível de compreensão do aluno, modificando desde o tipo de instrução fornecida até a adequação dos materiais disponibilizados.

Elogiar e fornecer feedback - enaltecer, por meio de ações verbais e não verbais, comportamentos apropriados do aluno durante a realização de uma tarefa. Salientar os aspectos positivos da conduta.

Desafiar - propor tarefas que apresentem nível de exigência dentro da Itens da escala

Zona de Desenvolvimento Proximal do aluno.

\section{Definição do componente}

Diferenciação psicológica - responder de forma individualizada às demandas dos alunos, valorizando o ponto de vista de cada educando. Focar no processo e não nos resultados, ajudando a criança a aprender algo além da tarefa a ser produzida.

Responsividade contingente - responder de forma antecipada e adequada ao nível de desenvolvimento do aluno.

Envolvimento afetivo - evidenciar, por meio de comportamentos verbais e não verbais, sentimentos em relação ao aluno.

Mudança - tecer comentários acerca do esforço e engajamento do 27 aluno na realização de uma tarefa, auxiliando-o a contrastar o seu desempenho atual com o desempenho anterior.

Fonte | Elaborado pelas autoras 
Embora versões da escala EAM tenham sido traduzidas e adaptadas por outros autores (CUNHA; ENUMO; CANAL, 2006; DIAS; ENUMO; MOREIRA; FÉLIX, 201 1), e publicadas em estudos anteriores (CUNHA; ENUMO; CANAL, 2006; NASCIMENTO, 2012 ; FÉLIX, 20131, não foi encontrada, na literatura nacional, a tradução, na íntegra, da escala para professores. Assim, com a autorização da autora C.S. Lidz, a escala EAM para professores foi traduzida livremente pela segunda autora.

$\bigcirc$ presente estudo caracteriza-se como uma pesquisa de natureza quase experimental, com um delineamento intrassujeito do tipo A-B IKENNEDY, 2005). Nesse contexto, o programa de capacitação, descrito posteriormente, compreendeu a Variável Independente (VI). Os comportamentos de mediação, emitidos pela professora e avaliados pela escala EAM para professores (LIDZ, 2003), se constituíram nas Variáveis Dependentes (VD).

Este estudo pode ser também classificado como de natureza qualitativa, uma vez que se traduz como uma pesquisa que envolve "[...] um conjunto de práticas materiais e interpretativas que dão visibilidade ao mundo" (DENZIN; LINCOLN, 2006, p. 17).

142 projeto de pesquisa foi submetido e aprovado pelo Comitê de Ética em Pesquisa da Universidade Federal do Rio Grande do Norte, CAAE: 27884614.2 .0000 .5292 (Parecer no 666.981). Após os acordos institucionais com a direção da escola, a pesquisa, desenvolvida entre janeiro e novembro de 20 14, foi dividida em cinco fases: (a) Treinamento do Assistente de Pesquisa; (b) Linha de Base; (c) Capacitação; (d) Intervenção e (e) Validade Social.

\section{Etapa 1: Treinamento da Assistente de Pesquisa}

objetivo do treinamento foi capacitar a assistente de pesquisa na utilização da escala EAM para professores. Esse instrumento de medida serve para avaliar o comportamento da professora, durante as atividades acadêmicas desenvolvidas com o aluno no contexto escolar. Participaram das sessões de treinamento ambas as autoras do presente artigo, o que envolveu procedimentos como discussões, análise de materiais videografados e leituras.

Após definido o repertório de comportamentos da professora, conforme descritos na escala, tanto a pesquisadora quanto a assistente de 
pesquisa codificaram, de forma independente, sessões videografadas na sala de aula de Aluizio. Vale ressaltar que o conteúdo dessas sessões foi utilizado como teste, não sendo, todavia, considerado nos resultados conclusivos da pesquisa. $\bigcirc$ término do treinamento ocorreu quando as sessões categorizadas pela assistente apresentaram índice de concordância de, no mínimo, 75\%, entre os observadores independentes.

\section{Etapa 2: Linha de Base}

A rotina escolar do aluno foi registrada durante 22 dias, utilizando-se para tanto um diário de campo e também de videogavação. Ao término dessas sessões de observação, tanto a mãe quanto a professora de Aluizio foram entrevistadas e supervisionadas pela pesquisadora, e preencheram a escala CARS. Nesse sentido, o objetivo da entrevista com a mãe de Alvizio foi identificar as potencialidades e dificuldades deste aluno no contexto doméstico. A entrevista com Ana teve como objetivo analisar sua rotina de trabalho em sala de aula, identificar as estratégias de ensino utilizadas com o aluno, assim como o seu nível de conhecimento sobre TEA. A escala CARS foi aplicada visando identificar as demandas sociocomunicativas e comportamentais do aluno, e, ainda, o seu grau de autismo. Esses elementos foram considerados no/para o planejamento da capacitação.

Utilizando-se da escala EAM para professores, a assistente de pesquisa procedeu à avaliação do repertório de comportamento de mediação da professora, durante as atividades acadêmicas. $\bigcirc$ processo de seleção dos segmentos codificados cumpriu os seguintes critérios: (1) atividade acadêmica deveria estar acontecendo; (2) apenas os dez primeiros minutos de cada atividade seria considerado. Após a identificação desses segmentos, foram selecionados, de forma aleatória, quatro vídeos.

$\bigcirc$ material videografado das sessões experimentais era entregue à assistente de pesquisa, que atuou como primeira avaliadora. Como segunda avaliadora, a pesquisadora teve a tarefa de categorizar 25 por cento do total das sessões experimentais. $\bigcirc$ cálculo do Índice de Concordância ou Índice de Fidedignidade das análises apresentadas por ambas - pesquisadora e assistente - foi baseado em Fagundes (1985). $\bigcirc$ índice médio de concordância foi de $75 \%(62-88 \%)$, indicando boa fidedignidade. 
Aprendizagem mediada na escolarização de educandos com autismo

A Linha de Base foi finalizada quando, por meio de inspeção visual, foi observada constância no repertório de comportamento mediador total da professora durante as atividades acadêmicas.

\section{Etapa 3: Capacitação}

Nessa etapa, a pesquisadora conduziu um programa de capacitação com a professora, tendo como base os comportamentos observados durante as sessões de Linha de Base, somados às demandas resultantes dos dados das sessões de observações, realizadas no ambiente de sala de aula, entrevistas e resultado do CARS.

programa de capacitação compreendeu a leitura de textos, a confecção de materiais didáticos e a análise de sessões de observação videogravadas. Esta metodologia de pesquisa, intitulada autoscopia (SADALLA; LAROCCA, 2004), implica o uso de procedimentos cujo objetivo é a autoavaliação do sujeito participante, por meio de imagens produzidas na videogravação. A cada encontro/sessão de intervenção, um trecho de uma cena era discutido e exibido para apreciação da professora, a fim de que ela

144 realizasse sua autoavaliação.

A intervenção ocorreu durante o período de um mês, perfazendo um total de seis horas. Nestes encontros, conduzidos antes da intervenção, cinco temáticas foram discutidas com a professora: (1) as características do autismo, (2) a Comunicação Alternativa e Ampliada; (3) as rotinas acadêmicas e o uso de recursos visuais; (4) a adaptação curricular e (5) a Aprendizagem Mediada.

\section{Etapa 4: Intervenção}

Após cada encontro de capacitação, Ana era instruída a aplicar as propostas curriculares discutidas com Aluizio durante a atividade acadêmica. Essas sessões eram filmadas e analisadas nos encontros de capacitação subsequentes. No total foram 66 horas de aulas gravadas. Para análise, foram considerados doze vídeos randomicamente selecionados, seguindo-se os mesmos critérios de seleção previamente explicitados. $\bigcirc$ encerramento da intervenção ocorreu quando foi percebida uma estabilidade nos níveis de mediação avaliados pela escala EAM para professores. 


\section{Etapa 5: Validade Social}

Ao término da pesquisa foram conduzidas entrevistas com a mãe e com a professora, com o propósito de analisar a validade social do estudo. Por validade social compreende-se a tentativa de se extrair dos participantes e/ou colaboradores os comportamentos que foram socialmente importantes após a pesquisa propriamente dita (KENNEDY, 2005).

\section{Resultados}

Duas perguntas norteadoras foram identificadas nessa parte do trabaIho: (1) Quais os efeitos do programa de capacitação na prática pedagógica da professora? (2) Quais os efeitos do programa de capacitação no desempenho acadêmico e social do aluno?

As respostas a essas questões foram derivadas dos diários de campo e das sessões videografadas no decorrer dos onze meses de realização da pesquisa.

Registros de campo produzidos durante a fase Linha de Base revelaram que o comportamento da professora era condizente com a pedagogia tradicional, inspirada em um modelo intelectualista e enciclopédico, preponderante no início do século XIX (SAVIANI, 2007). Nessa prática, marcada pelas exposições exacerbadas de conteúdos, o mestre (professor) é visto como autoridade máxima em sala de aula e os conteúdos apresentados trazem escassa relação com o cotidiano ou a realidade social dos educandos.

Nessa perspectiva, as atividades desenvolvidas pela docente eram, essencialmente, voltadas para a realização de cópias de conteúdos do quadro e resolução de tarefas no caderno e/ ou livro didático. Os alunos se sentavam enfileirados e havia poucas discussões sobre os assuntos acadêmicos na sala de aula, conforme exemplificado no registro de campo abaixo:

Aula de Religião. A professora passou um filme e fez uma breve explicação. O filme tratava da 'Última Ceia de Cristo'. Na sequência, ela entregou uma follha de ofício para os alunos e pediu que ilustrassem o que Deus representava. Em seguida fez os modelos de desenhos no quadro: União, Espírito Santo, Paz, etc. Os alunos copiaram os modelos do quadro. A professora se aproximou de Aluizio e disse: 'E tu, Aluizio, o que vamos fazer?' Em seguida, pegou em sua mão e fez o desenho por ele, sem nada dizer nem olhá-lo (DIÁRIO DE CAMPO, 2014). 
Como previamente assinalado no presente manuscrito, três classes de comportamentos mediadores são essenciais para que aconteça uma situação de aprendizagem: a intencionalidade/reciprocidade, o significado e a transcendência. A cena acima descrita sugere, entretanto, que a docente pouco mediou a aprendizagem. Em termos de intencionalidade, ela não salientou os objetivos de assistir ao filme. Assim, poderia, por exemplo, falar sobre a importância de conhecer a figura de Cristo para compreender a história da religião ou ressaltar segmentos da história em que os alunos deveriam ficar atentos, visto que fariam, posteriormente, uma atividade escrita.

Em termos de reciprocidade, a professora desconsiderou os comportamentos dos alunos diante do filme. Em outras palavras, diante das atitudes de desinteresse da turma, Ana poderia, por exemplo, ter pausado o filme e conversado com os alunos, com vistas a identificar o motivo de seu desinteresse. $\bigcirc$ comportamento mediador de significação também foi insatisfatório, visto que a docente falhou em demonstrar à turma a importância de aprender o conteúdo do filme.

Por fim, não foram observados comportamentos que favorecessem a generalização do aprendizado (transcendência). Nessa perspectiva, ela pode146 ria, por exemplo, propor que os alunos desenhassem o que Deus representava, sem apresentar-thes um modelo prévio. Em seguida, ancorada no conteúdo abordado no filme, discutir com o grupo os desenhos de cada um.

A carência de comportamentos mediadores fica, ainda, mais crítica quando é analisada a interação da professora com Alvizio na cena acima descrita. Pegar na mão do menino e copiar a imagem de "Deus", sem incluir outros comportamentos de mediação, dificilmente favoreceria a aprendizagem.

Na maior parte do tempo, Aluizio não participava ativamente das atividades de sala, e permanecia ocioso. Nesses contextos, eram tipicamente observados comportamentos não adaptativos do aluno, como deitar-se no chão, tirar as sandálias, morder a roupa ou balançar o corpo. Como salienta Kauffman (2005), os problemas de conduta não devem ser considerados apenas como ações inapropriadas, mas como interações impróprias entre as crianças e outras pessoas. Dessa forma, o comportamento de Aluizio sugere que as tarefas realizadas na escola eram pouco significativas ou desafiadoras para ele. De fato, as raras atividades adaptadas para ele eram infantilizadoras, trazendo parca relação com conteúdos que ele já dominava. A Figura 1 
a seguir retrata uma das atividades feitas por Aluizio durante a fase Linha de Base:

\section{Figura 1}

\section{Atividade de colagem proposta para Aluízio}

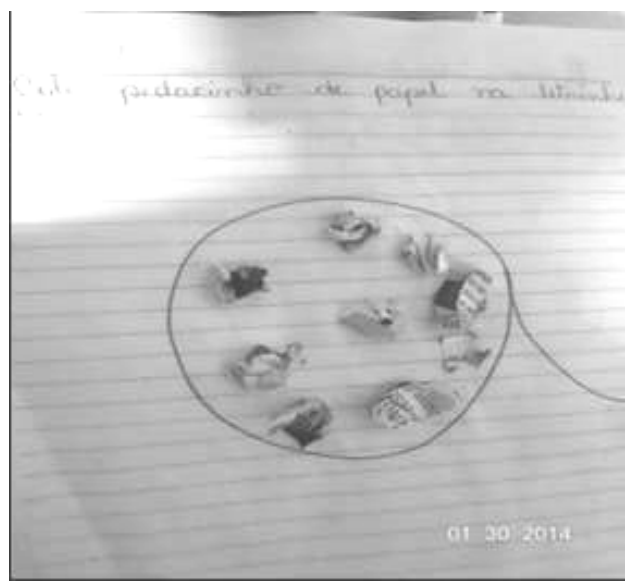

Fonte | Arquivo pessoal

A linguagem adotada pela professora no enunciado da questão ("cole o pedacinho de papel na letrinha $a^{\prime \prime}$ ) e o teor da atividade se reportam a tarefas próprias da Educação Infantil. Observa-se a inadequação dessa proposta, uma vez que a mãe revelou que Alvizio já era alfabetizado, conforme sugere o segmento de entrevista abaixo:

No computador ele fica no Youtube. Bota jogo, uma hora tá no programa no RNTV, outra hora tá no Fátima Bernardes, outra hora tá no Silvio Santos. Ele coloca tudo. Ele escreve tudo. Ontem eu fiquei olhando, quando dei fé tava lá passando negócio da maior páscoa do mundo lojas americanas e eu digo "menina" e ele com a mãozinha esquerda só escrevendo. Ele escreve. Ele entra no Youtube e bota tudo que ele quer. Aluizio tá fazendo o alfabeto todinho. Ele escreve tudo certo [...] Ele só não escreve com o lápis [...] (MÃE, 2014).

Os dados de Linha de Base indicaram que inexistia, no contexto escolar estudado, um planejamento específico para Aluizio. Suas demandas, 
como a falta de comunicação, socialização e participação nas atividades acadêmicas desapareciam, em uma sala de aula em que ocupava, por vezes, apenas um lugar físico. As atividades descontextualizadas propostas ao aluno pareciam ter como propósito primordial mantê-lo ocupado. Esses dados são semelhantes aos achados de outros estudos, que sugerem haver empobrecimento curricular para alunos com autismo inseridos em escolas regulares (CRUZ, 2009; NUNES; LEMOS, 2009; GOMES; MENDES, 2010; LUNARDI-MENDES, 2011 , CORRÊA NETTO, 2012 ; PEREIRA, 2014).

Além da falta de mediação por desafio, caracterizada pela carência de atividades condizentes com o nível de desenvolvimento de Aluizio, registros de campo revelaram que a professora pouco consequenciava o comportamento do aluno. Assim, não foram registrados, durante a fase Linha de Base, momentos em que Ana tivesse parabenizado o desempenho do aluno (mediação por elogio e feedback), tampouco salientado o seu progresso (mediação por mudança) nas poucas atividades acadêmicas realizadas. Adicionalmente, raros episódios de mediação por envolvimento afetivo, como a proximidade física, o abraço ou palavras de carinho dirigidas ao aluno foram observadas durante a fase Linha de Base. Esse padrão de comportamento pode, em parte, 148 ser explicado pela falta de compreensão da síndrome, que levava a docente a distanciar-se de Aluizio, conforme sugere a fala abaixo:

[...] deveria ter alguém especializado nessa área o qual pudesse entender mais o problema dele. É muito difícil trabalhar com ele por quê? Porque você quase não entende nada, então como trabaThar uma criança se você não entende sobre o problema daquela criança? [...] (PROFESSORA, 2014).

Dados das entrevistas com a mãe e com Ana, assim como os registros de campo, indicaram que Aluízio: (a) apresentava pouca autonomia para realizar as tarefas acadêmicas; (b) não realizava atividades acadêmicas condizentes com sua idade/série; e (c) não tinha uma forma sistematizada de comunicação com os demais.

Com o objetivo de aumentar a frequência de participação do aluno nas atividades observadas, ampliar sua autonomia e sua comunicação, foi delineado um plano de intervenção junto à professora. Nesse plano, foram consideradas as potencialidades, déficits e interesses da criança apontados 
pela mãe, pela professora por meio das entrevistas, do CARS e dos registrados de diário de campo.

Durante a capacitação, a importância da adaptação curricular foi abordada. Essa temática parece ter influenciado o comportamento da professora, uma vez que ela passou a aumentar o nível de exigência das atividades propostas para Aluizio, conforme ilustrado a seguir:

\section{Figura 2}

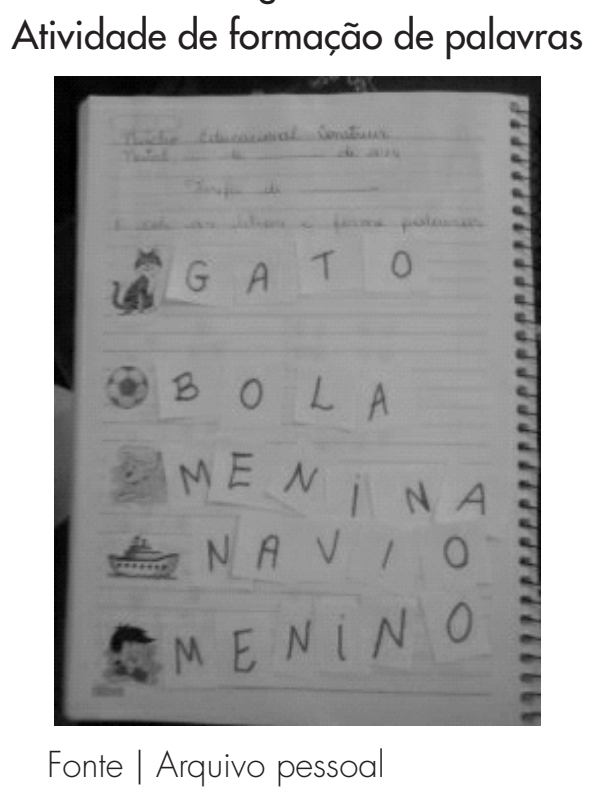

Na atividade mostrada na Figura 2, Aluizio conseguiu, com sucesso, colar as letras que formavam as palavras correspondentes a cada imagem. Tendo como base a sua dificuldade em utilizar o lápis, conforme relatado pela mãe, a professora propôs o uso de letras móveis para a produção da escrita. Nessa perspectiva, a natureza da lição e a seleção dos materiais favoreceram a participação ativa do aluno, caracterizando a mediação por diferenciação psicológica.

A capacidade de o professor balancear as demandas dos alunos que evidenciam necessidades especiais com aqueles que apresentam desempenho superior é um dos comportamentos de mediação por responsividade contingente (LIDZ, 2003). Após a intervenção, esse comportamento foi observado em 
Ana, que passou a contar com a colaboração dos colegas de turma para auxiliar Aluizio nas atividades de Artes, Português e Matemática. Nesse processo, que favoreceu a interação do educando com os demais alunos, a professora tipicamente ensinava ao colega como deveria realizar a tarefa com Alvizio. As orientações consistiam em não dizer a resposta a ele, estimular a sua fala, conduzir a tarefa de modo que ele a realizasse e fornecesse feedback. Nessa perspectiva, são observados comportamentos de mediação por elogio e responsividade contingente.

Adicionalmente, a professora afixou uma prancha de comunicação com pictogramas móveis na parede, ao lado da carteira de Alvizio. Essa prancha passou a ser utilizada pela docente e alunos durante as interações comunicativas com o menino.

A Figura 3 mostra Aluizio realizando atividade ao lado de uma colega, tendo a prancha de comunicação afixada ao seu lado.

\section{Figura 3}

Aluízio realizando atividade de identificação de quantidades com apoio de colega

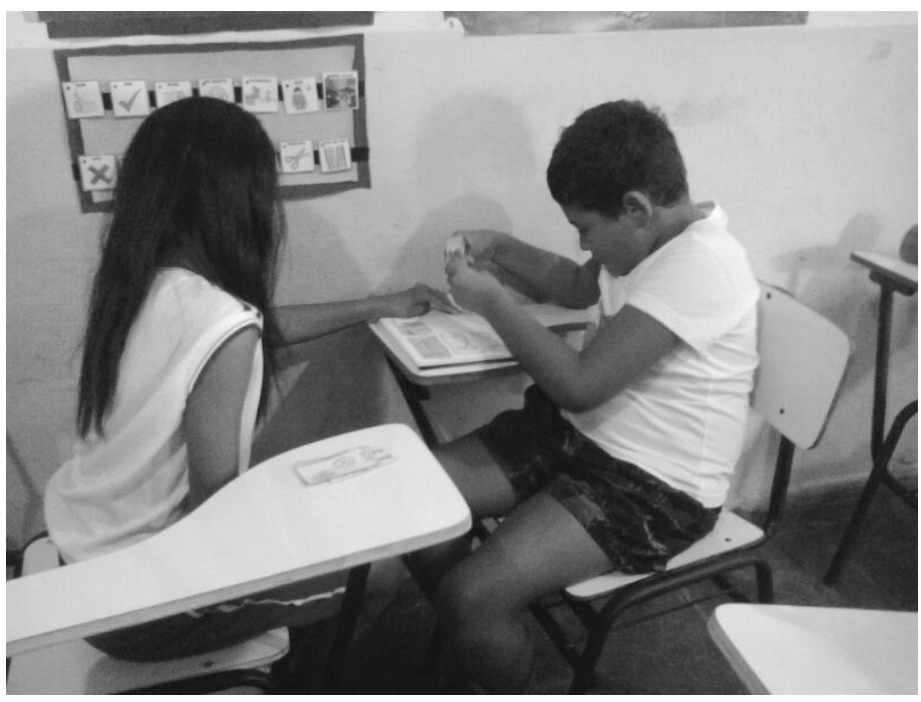

Fonte | Arquivo pessoal 
Com o objetivo de avaliar os efeitos da intervenção no comportamento mediador da professora durante a realização de atividades acadêmicas, foi utilizada a escala EAM de Lidz (2003). A aplicação do instrumento, pela assistente de pesquisa, foi feita através da análise de segmentos videografados com duração de dez minutos. Vale salientar que foram consideradas apenas as interações da professora com Aluizio, não sendo pontuados os seus comportamentos dirigidos aos outros alunos.

Conforme previamente descrito, cada componente da escala pode ser avaliado individualmente, recebendo pontuação média máxima de 4 pontos e, mínima, de 1. A média total de mediação é calculada quando são agrupados os doze componentes avaliados na escala, resultando em pontuação máxima de 48 e, mínima, de 12.

nivel de mediação total da docente durante a LB e Intervenção está apresentado na Figura 4.

\section{Figura 4}

\section{Pontuação da Mediação da professora durante atividade acadêmica}

Total de Mediação

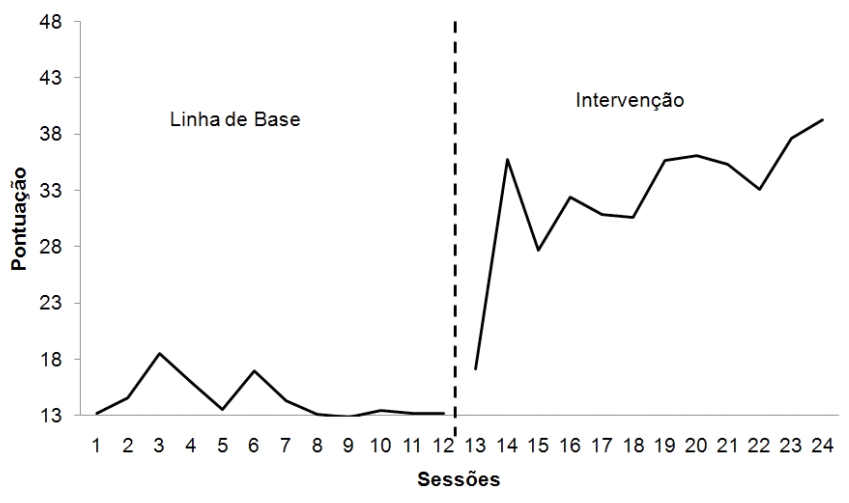

—Nivel de mediação MLE

De acordo com Lidz (2003), o emprego dos doze comportamentos previamente descritos é o que caracteriza um comportamento mediador. $\bigcirc$ valor mínimo de mediação atingido pela docente foi 13, na primeira sessão de LB, e o máximo, 18,5. Durante a intervenção, o grau de mediação mínimo foi de 17,16 e, máximo, de 39,25. Adicionalmente, observa-se uma tendência 
crescente de mediação pela professora no decorrer da fase Intervenção. Em outras palavras, a professora passou a ser mais transcendente, a regular, de forma mais sistemática, as tarefas, a ser mais diretiva, a elogiar, a desafiar, além de responder de maneira mais afetiva ao aluno com autismo. Estas informações são ratificadas pelos dados qualitativos previamente descritos, que sinalizam uma mudança no comportamento mediador da docente, após a intervenção.

Ao término da pesquisa, foram conduzidas entrevistas com a mãe e com a professora, com o objetivo de analisar a validade social do estudo. A satisfação da mãe com os resultados da pesquisa está evidenciada na fala a seguir, quando salienta os avanços observados no comportamento do filho, após o programa de intervenção:

Eu acho que ele avançou bastante, pelo menos aprendeu mais, eu sinto que ele está mais tranquilo, tá conhecendo mais as coisas. Antigamente eu dizia [Aluizio] pegue uma colher pra mamãe, ele ficava todo errado, trazia uma faca, um garfo, hoje ele já sabe o significado das coisas, se eu pedir uma colher ela já sabe o que é e pega. Se eu disser pegue ali um pano de prato, ele vai e pega, ele já tá sabendo. Não que vocês tenham ensinado ele assim, entendeu?! Mas eu digo assim, que ele tá se acostumando, conhecendo as coisas, entendendo o pra que serve, entendeu? ! Hoje mesmo, eu fui escovar os dentes com ele, eu disse: vixe, a pasta acabou, ele olhou pra mim e disse: lixo! Então, ele já sabe que acabou, vai pro lixo. Já tá interagindo, entendendo as coisas, bem melhor (MẪE, 2014).

comportamento de "ficar mais tranquilo" e de associar os objetos aos nomes também foram percebidos em sala de aula, conforme os registros de campo. Na perspectiva da mãe, Aluizio parece ter se tornado mais comunicativo e compreendido pelas pessoas ao seu redor, além de ter dado indícios de que entendia melhor o outro.

Em termos de aprendizagem, a mãe relata:

Eu também achei que melhorou, com certeza! Melhorou muito, a questão do conhecimento das palavras, eu acho que ele já escreve tudo, não tem dificuldade em escrever nada. Eu acho que ele melhorou muito! (MÃE, 2014). 
Esses dados são corroborados com os registros de campo. Após a professora passar a considerar as potencialidades da criança e a aumentar o nível de exigência das atividades, mudanças no comportamento de Alvizio foram observadas.

A intervenção, na perspectiva da professora, foi também frutífera, conforme salientado no segmento a seguir:

Sim, como já falei desde o início, eu não sabia o que era autismo, né?! Então, quando você chegou, que apareceu na minha sala de aula e trouxe materiais, aos quais eu tive conhecimento, fui aprendendo e me aprofundando cada vez mais, fui criando um gosto, uma curiosidade, e daí ficou bem mais fácil trabalhar com o aluno, porque eu já sabia, já tinha conhecimento de alguma coisa. E diante dos avanços, a cada dia eu venho notando, que graças a Deus tanto pelo meu lado, que venho entendendo um pouco mais sobre o autismo, quanto ele, vem desenvolvendo cada dia mais e mais e diante da pesquisadora, eu só tenho a agradecer, ela tá de parabéns pelo trabalho dela, muito bom (PROFESSORA, 2014a).

A fala da professora destaca o aspecto positivo da capacitação e como ela foi importante para a sua tomada de consciência com relação à pessoa com TEA. Adicionalmente, esse dado remete à importância da formação em serviço e da presença de um colaborador na sala de aula, conforme assinalado por outros estudos (CAPELLINI; MENDES, 2007; DANTAS, 2009; GIARDINETTO, 2009; GOMES, 2011 ; CORRÊA NETO, 201 2; PEREIRA, 20 14 I.

\section{Considerações finais}

Pesquisas nacionais sugerem que alunos com autismo apresentam limitado desenvolvimento acadêmico e dificuldades em interagir socialmente com seus pares, em contextos regulares de ensino. Dentre os fatores responsáveis por esse fenômeno está a falta de informações sobre a síndrome e o desconhecimento de estratégias interventivas eficazes. Nessa perspectiva, é imprescindível capacitar o professor a desenvolver comportamentos mediadores que viabilizem a aprendizagem do educando. Assim, o objetivo do presente estudo foi analisar os efeitos de uma proposta de intervenção baseada na Experiência de Aprendizagem Mediada (EAM) no desempenho acadêmico 
e social de Alvizio, um aluno de nove anos, tendo a sua professora como agente mediador.

Registros de campo e dados de entrevistas indicaram que Ana, a professora, desconhecia a sintomatologia do autismo e falhava em planejar atividades condizentes com o nível de desenvolvimento cognitivo de Aluizio. Por meio de um delineamento de pesquisa quase experimental, foi possível observar o baixo nível de comportamentos mediadores adotados pela professora durante as atividades acadêmicas analisadas.

A partir dos resultados de Linha de Base, foi delineado um programa de capacitação para a docente, tendo como temáticas o autismo, a adaptação curricular, a Comunicação Alternativa e os critérios de EAM. Nessa fase, Ana pôde, ainda, observar a sua prática por meio do procedimento de autoscopia, além de produzir, com o auxílio da pesquisadora, materiais didáticos.

A intervenção, de cunho colaborativo, teve uma marca dialógica que orientou todo o estudo realizado, desde os aspectos teóricos trabalhados até a execução de tarefas práticas. Essa formação em serviço parece ter levado a docente a pensar e a reestruturar sua aula. Assim, os registros de campo indicaram que ela passou a planejar atividades para Aluizio, respeitando as suas especificidades, após a capacitação. Desse modo, foi observado aumento no nível de exigência das tarefas para a criança e mais participação em atividades de grupo.

nível de mediação da professora durante as atividades acadêmicas aumentou, após a implementação do programa, conforme avaliado pela escala EAM para professores. Esse padrão de comportamento docente possivelmente impactou as respostas de Aluizio, que evidenciou avanços acadêmicos e sociais. Assim, o aluno passou a reconhecer as letras e a grafia de algumas palavras, a escrever o seu nome de forma independente e a participar de atividades de grupo, favorecendo a sua interação com seus pares.

Dados das entrevistas conduzidas com a professora e com a mãe do educando indicaram que ambas estavam satisfeitas com os resultados da intervenção.

É relevante, por fim, pontuar as limitações identificadas no presente estudo. Primeiramente, a pesquisa restringiu-se a avaliar o comportamento da díade (professor-aluno) no contexto da sala de aula, durante atividades acadêmicas. Não foi analisada, nessa perspectiva, a generalização dos 
comportamentos aprendidos para outros cenários. Adicionalmente, as pesquisadoras falharam em conduzir sessões de follow-up, a fim de verificar se a professora deu continuidade ao trabalho.

Concluindo, vale discutir se o contexto de aplicação da escala foi adequado. De acordo com as orientações de Carol Lidz, a autora do instrumento, a escala EAM para professores foi delineada para ser aplicada com educandos com desenvolvimento típico, sendo avaliado o comportamento mediador do professor com o grupo de alunos. Na presente pesquisa, os diferentes padrões de interação da professora com o educando com autismo, quando comparados com o restante do grupo, eram evidentes. Assim, foi acordado que, ao invés de avaliar os níveis de mediação com todos os alunos, seria considerado apenas o seu comportamento dirigido ao educando com autismo. Nesse sentido, seria relevante avaliar se o nível de mediação da professora com o grupo, como um todo, sofreu mudanças. Afinal, o aluno estava em uma sala regular, sendo escolarizado com outros alunos.

É imperativa a condução de outros estudos nacionais que empreguem instrumentos e/ou ações que possam complementar e/ou favorecer a aprendizagem de educandos com TEA. É primordial mobilizar a inclusão escolar do aluno com TEA, assim como de todos os aprendizes, não apenas de forma social e/ou funcional, mas também acadêmica, nos anos inicias do Ensino Fundamental e nos demais anos escolares e, acima de tudo, prepará-los para a vida.

\section{Referências}

CAPELLINI, Vera Lúcia; MENDES, Enicéia. O ensino colaborativo favorecendo o desenvolvimento profissional para a inclusão escolar. Revista de Educação Educare, Cuiabá, v. 2, n. 4, p. $113-128$, jul./dez. 2007.

CHRISTENSEN, Deborah; BAIO, Jon; BRAUN, Kim; BILDER, Deborah; CHARLES, Jane; CONSTANTINO, John; DANIELS, Julie; DURKIN, Maureen; FITZGERALD, Robert; KURZIUSSPENCER, Margaret; LEE, Li-Ching; PETTYGROVE, Sydney; ROBINSON, Cornelia; SCHULZ, Eldon; WELLS, Cris; WINGATE, Martha; ZAHORODNY, Walter; YEARGINALLSOPP, Marshalyn. Prevalence of autism spectrum disorder among children aged 8 years - autism and developmental disabilities monitoring network, 11 sites, United States, 2012.

MMWR Surveill Summ, Atlanta, v. 65, n. 3, p. 1-26, abr. 2016. 
CORRÊA NETTO, Márcia. A comunicação alternativa e a aprendizagem de crianças com autismo, Asperger e Angelman: formação continuada de profissionais de Educação e Saúde. $2012.290 f$. Dissertação (Mestrado em Educação) - Programa de Pós-Graduação em Educação, Universidade do Estado do Rio de Janeiro. Rio de Janeiro, 2012.

CRUZ, Talita Souza Umbelino Rodrigues da. Acompanhamento da experiência escolar de adolescentes autistas no ensino regular. 2009. 139f. Dissertação (Mestrado em Educação) - Programa de Pós-Graduação em Educação, Universidade Metodista de Piracicaba, Piracicaba, 2009.

CUNHA, Ana Cristina Barros da. Avaliação cognitiva de criança com baixa visão leve por procedimentos tradicional e assistido e suas relações com comportamentos e mediação materna. 2004. 429f. Tese (Doutorado em Psicologia) - Programa de Pós-graduação em Psicologia, Centro de Ciências Humanas e Naturais, Universidade Federal do Espírito Santo, Vitória, 2004.

CUNHA, Ana Cristina Barros da; ENUMO, Sônia Regina Fiorim; CANAL, Claudia Patrocínio Pedroza. Operacionalização de escala para análise de padrão de mediação materna: um estudo com díades mãe-criança com deficiência visual. Revista Brasileira de Educação Especial, Marília, v. 12, n. 3, p. 393-412, 2006.

CUNHA, Ana Cristina Barros da; GUIDORENE, Bárbara Schätchter. Interação terapêutica em saúde mental usando a teoria da aprendizagem mediada. Psicologia em Estudo, Maringá, v. 14, n. 3, p. 455-463, jul./set. 2009.

CUNHA, Ana Cristina Barros da; MAGALHÃES, Joyce Goulart. Oficina de aprendizagem mediada: uma proposta de reflexão da prática pedagógica em Educação Inclusiva. Curitiba: Juruá, 2011.

DANTAS, Aline Paiva. Entre o educar e o constituir: efeitos possíveis da educação de uma criança com transtorno grave de desenvolvimento. 2009. 199f. Dissertação Mestrado em Psicologia Clínica) - Programa de Estudos Pós-Graduação em Psicologia Clínica, Pontifícia Universidade Católica de São Paulo. São Paulo, 2009.

DENZIN, Norman; LINCOLN, Yvonna. Handbook of qualitative research. London: Sage, 2006.

DIÁRIO de campo. Natal, Rio Grande do Norte, 14, fevereiro, 2014.

DIAS, Tatiane; ENUMO, Sônia Regina; MOREIRA, Mirian; FÉLIX, Fabiana. Mediação na prática pedagógica de professores dos ciclos iniciais do ensino fundamental. In: GENTIL, Heloisa; MICHELS, Maria Helena. Práticas Pedagógias: política, currículo e espaço escolar. Araraquara: Junqueira \& Marin, 2011. 
FAGUNDES, Antônio. Descrição, definição e registro de comportamentos. São Paulo: Edicon, 1985.

FARIAS, lara Maria; MARANHÃO, Renata Veloso; CUNHA, Ana Cristina Barros da. Interação professor-aluno com autismo no contexto da educação inclusiva: análise do padrão de mediação do professor com base na Teoria da Experiência de Aprendizagem Mediada (Mediated Learning Experience Theory). Revista Brasileira Educação Especial, Marília, v. 14, n. 3, p.365-384, set./dez. 2008.

FÉLIX, Fabiana Muniz Mello. O Professor em formação: a mediação pedagógica de estagiárias de pedagogia. 2013. 165f. Dissertação (Mestrado em Educação) - Programa de Pós-Graduação em Educação, Universidade do Estado de Mato Grosso, Cáceres, 2013.

FEUERSTEIN, Reuven; RAND, Yaacov; JENSEN, Mogens; KANIEL, Shlomo; TZURIEL, David. Prerequisites for assessment of learning potential: The LPAD model. In: LIDZ, Carol (Org.). Dynamic assessment: an interactional approach to evaluating learning potential. New York/London: Guilford Press, 1987.

FONSECA, Vitor da. Pedagogia mediatizada: transferência de estratégias para novas aprendizagens. São Paulo: Salesiana, 2002.

GIARDINETTO, Andréa. Educação do aluno com autismo: um estudo circunstanciado da experiência escolar inclusiva e as contribuições do currículo funcional natural. 2009. 194f. Tese (Doutorado em Educação) - Programa de Pós-Graduação em Educação, Universidade Estadual Paulista, Marília, 2009.

GOMES, Camila; MENDES, Enicéia. Escolarização Inclusiva de Alunos com Autismo na Rede Municipal de Ensino de Belo Horizonte. Revista Brasileira de Educação Especial, Marília, v. 16, n. 3, p. 375-396, set./dez. 2010.

GOMES, Rosana Carvalho. Interações comunicativas entre uma professora e um aluno com transtorno invasivo do desenvolvimento na escola regular. 2011 . 157f. Dissertação (Mestrado em Educação) - Programa de de Pós-Graduação em Educação, Universidade Federal do Rio Grande do Norte, Natal, 2011.

KAUFFMAN, James. Characteristics of emotional and behavioral disorders of children and youth. 8th edition. New Jersey: Pearson Educational, 2005.

KENNEDY, Craig. Single-case designs for educational research. Boston: Pearson Education, Inc, 2005.

LIDZ, Carol. Early childhood assessment. Hoboken: John Wiley \& Sons, 2003. 
Aprendizagem mediada na escolarização de educandos com autismo

LUNARDI-MENDES, Geovana. As práticas escolares nos cadernos escolares: registros de inclusão? In: PLETSCH, Márcia; DAMASCENO, Allan (Org.). Educação Especial Inclusão Escolar: Reflexões sobre o fazer pedagógico. Seropédica, RJ: Editora da UFRRJ, 2011.

MÃE. Entrevista. Natal (Rio Grande do Norte), 31 mar. 2014.

MAGALHÃES, Joyce Goulart. CUNHA, Nathália Moreira da. SILVA, Suzanli Estef da. Plano Educacional Individualizado (PEI) como instrumento na aprendizagem mediada: pensando sobre práticas pedagógicas. In: GLAT, Rosana; PLETSCH, Márcia (Org.). Estratégias educacionais diferenciadas para alunos com necessidades especiais. Rio de Janeiro: EdUERJ, 2013. P.33-48.

NASCIMENTO, Renata Cristina. Práticas pedagógicas de professores de $1^{\circ}$ ano do ensino fundamental: concepções sobre a inclusão de crianças de seis anos, sua mediação e avaliação de aprendizagem. 2012. 129f. Dissertação (Mestrado em Educação) - Programa de Pós-Graduação em Educação, Universidade do Estado de Mato Grosso, Cáceres, 2012.

NEVES, Anderson Jonas das; ANTONELLI, Carolina de Santi; SILVA, Mariana Girotto Carvalho da; CAPELLINI, Vera Lúcia Messias Fialho. Escolarização formal e dimensões curriculares para alunos com autismo: o estado da arte da produção acadêmica brasileira.

Educação em Revista, Belo Horizonte, v. 30, n. 2, p. 43-70, abr./jun. 2014.

NUNES, Débora Regina de Paula; LEMOS, Jane. Os desafios da inclusão no ensino regular: criança com autismo e características de hiperlexia. Revista Educação em Questão, Natal, v. 34, n. 20, p. 63-80, jan./abr. 2009.

NUNES, Débora Regina de Paula, AZEVEDO, Mariana Queiroz Orrico. SCHMIDT, Carlo. Inclusão educacional de pessoas com Autismo no Brasil: uma revisão da literatura. Revista Educação Especial, Santa Maria, v. 26, n. 47, p. 557-572, set./dez. 2013.

OLIVEIRA, Juliana; PAULA, Cristiane Silvestre de. Estado da arte sobre inclusão escolar de alunos com transtornos do espectro do autismo no Brasil. Cadernos de Pós-graduação em Distúrbios do Desenvolvimento, São Paulo, v. 12, n. 1, p. 53-65, 2012. Disponível em: <http://www.mackenzie.br/fileadmin/Graduacao/CCBS/Pos-Graduacao/Docs/ Cadernos/Volume_12/2o_vol_12/Artigo6.pdf>. Acesso em: 6 jan. 2016

PAULA, Cristiane; FOMBONNE, Eric; GADIA, Carlos; TUCHMAN, Robert; ROSANOFF, Michael. Autism in Brazil: perspectives from science and society. Revista da Associação Médica Brasileira, São Paulo, v. 57, n. 1, p. 2-5, jan./fev. 2011. 
PEREIRA, Alessandra; RIESGO, Rudimar Santos; WAGNER, Mario Bernardes. Autismo infantil: tradução e validação da Childhood Autism Rating Scale para uso no Brasil. Jornal de Pediatria, Porto Alegre, v. 84, n. 6, p. 487-494, dez. 2008.

PEREIRA, Débora Mara. Análise dos efeitos de um plano educacional individualizado no desenvolvimento acadêmico e funcional de um aluno com transtorno do espectro do autismo. 2014. 178 f. Dissertação (Mestrado em Educação) - Programa de de PósGraduação em Educação, Universidade Federal do Rio Grande do Norte, Natal, 2014.

PROFESSORA. Entrevista. Natal (Rio Grande do Norte), 31 mar. 2014.

PROFESSORA. Entrevista. Natal (Rio Grande do Norte), 6 nov. 2014a.

SADALLA, Ana Maria; LAROCCA, Priscila. Autoscopia: um procedimento de pesquisa e de formação. Educação e Pesquisa, São Paulo, v. 30, n. 3, p. 419-433, set./dez. 2004.

SAVIANI, Dermeval. História das ideias pedagógicas no Brasil. Campinas: Autores Associados, 2007.

VIGOTSKI, Lev Semiónovich. Obras Escogidas V: fundamentos de defectologia. Madrid: Visor, 1997.

YEOW, Kok Siat. Developing Children's Cognitive Functions and Increasing Learning Effectiveness: an intervention using the bright start cognitive curriculum for young children. 2011. 260f. Tese (Doutorado em Educação) - Curso de Educação, Universidade de Durham, Durham, 2011 . Disponível em: <http://etheses.dur.ac.uk/625/1/E-THESIS-_24_ Jan_2011final_corrections_no_marking_.pdfẹDD29+>. Acesso em: 2 jun. 2014.

Profa Ms. Cláudia Roberto Soares de Macêdo Professora da Rede Público de Ensino do Estado do Rio Grande do Norte

Universidade Federal do Rio Grande do Norte Departamento de Fundamentos e Políticas da Educação

Programa de Pós-Graduação em Educação Grupo de Pesquisa de Educação de Pessoas com Necessidades Especiais E-mail | claudianata|@hotmail.br

Profa Dra Débora Regina de Paula Nunes Universidade Federal do Rio Grande do Norte Departamento de Fundamentos e Políticas da Educação 
Artigo

Aprendizagem mediada na escolarização de educandos com autismo

Programa de Pós-Graduação em Educação Grupo de Pesquisa de Educação de Pessoas com Necessidades Especiais E-mail | deboranunes@ufrnet.br

Recebido 20 jun. 2016

Aceito 12 ago. 2016 